\title{
Concurrent validation of the OMNI-Resistance Exercise Scale of perceived exertion with elastic bands in the elderly
}

\author{
Juan C. Colado ${ }^{\mathrm{a}, \mathrm{b}}$, , Filipa M. Pedrosa ${ }^{\mathrm{b}, \mathrm{c}}$, Alvaro Juesas ${ }^{\mathrm{a}}$, Pedro Gargallo ${ }^{\mathrm{a}}$, Juan J. Carrasco ${ }^{\mathrm{d}}$, Jorge Flandez ${ }^{\mathrm{e}}$, \\ Matheus U. Chupel ${ }^{\mathrm{c}, \mathrm{f}}$, Ana M. Teixeira ${ }^{\mathrm{c}}$, Fernando Nacleriog \\ ${ }^{a}$ Research Group in Prevention and Health in Exercise and Sport, University of Valencia, Spain \\ ${ }^{\mathrm{b}}$ Research Unit in Sport and Health, University of Valencia, Spain \\ ${ }^{c}$ Research Center for Sport and Physical Activity, Faculty of Sport Science and Physical Education, University of Coimbra, Portugal \\ ${ }^{\mathrm{d}}$ Department of Physiotherapy, University of Valencia, Valencia, Spain \\ e Institute of Education Sciences, Physical Education and Sports Degree, Austral University of Chile, Valdivia, Chile \\ ${ }^{\mathrm{f}}$ CAPES Foundation, Ministry of Education, Brazil \\ ${ }^{g}$ Department of Life and Sport Science, University of Greenwich, United Kingdom
}

\section{A R T I C L E IN F O}

Section Editor: Marzetti Emanuele

\section{Keywords:}

RPE

Heart rate

Applied force

Resistance training

\begin{abstract}
A B S T R A C T
Purpose: To examine the concurrent validity of the OMNI-Resistance Exercise Scale of perceived exertion using elastic bands in elder population.

Methods: Twenty-six participants performed three separate sets of 15 repetitions (low- medium- and high-intensity) for 4 different exercises ( 2 for the upper-limb and 2 for the lower limb), over two different testing sessions. The criterion variables were heart rate and applied force (average and maximum). In addition to these dependent variables, the active muscle and overall body OMNI-RES for elastic bands scores were collected at the end of each repetition.

Results: Significant differences in heart rate, applied force and OMNI-RES scores between the low- and high-intensity sets were observed. For all the four exercises, high intensity sets elicited higher heart rate, applied force, and RPE compared to the medium and the low overloads. Intraclass correlation coefficient was 0.79 in heart rate and ranged $0.69-0.80$ in OMNI-RES Scale and 0.76-0.86 for the applied force.

Conclusion: A strong positive and linear relationship was observed between the rating of perceived exertion and both heart rate and applied force. The OMNI-RES scale with elastic bands demonstrated to be a valid method for assessing the perceived exertion during resistance exercises and consequently represent a useful tool for prescribing exercise intensity to the elderly.
\end{abstract}

\section{Introduction}

Aging is characterized by a loss of muscle strength and physical functioning (Rossi et al., 2017), which leads to a decrease in the performance of instrumental daily activities, independence and quality of life and, consequently, an increase in the risk of falls, morbidity and mortality in older adults (OA) (Delmonico et al., 2007; Mally et al., 2011). Resistance training (RT) has well-established positive effects to decreasing fat mass and attenuating progressive loss of fat-free mass in elderly (Chodzko-Zajko et al., 2009). Even though, the use of free weights and machines is currently very popular among coaches and clinicians these devices are not always feasible for OA, who may need specific and strong personalized support. Indeed, it has been demonstrated that the attrition rate during the first year of training using free weight is approximately $50 \%$ in OA (Colado and Triplett, 2008). Conversely, elastic resistances represent alternative very easy to use, transport and maintain devices that in addition have showed a reduced risk of injury in "healthy" and "not healthy" elderly (Martins et al., 2013). Several recent publications have highlighted the advantages of using elastic material for increasing strength and performance in OA. José and Dal Corso (2016) indicate that using elastic materials in healthcare settings is an effective method, easier to transport and store (in settings that often have very limited space) and are significantly less expensive.

\footnotetext{
* Corresponding author at: Juan C. Colado. Research Group in Prevention and Health in Exercise and Sport, University of Valencia, Spain.

Email addresses: juan.colado@uv.es (J.C. Juan C. Colado); Juan.J.Carrasco@uv.es (J.J. Juan J. Carrasco); ateixeira@fcdef.uc.pt (A.M. Ana M. Teixeira); F.J.Naclerio@greenwich.ac.uk (F. Fernando Naclerio)
} 
Furthermore, elastic resistances have elicited higher intrinsic motivation in healthcare practitioners to advocate for strength exercises that can be even performed at home (Polyte et al., 2015).

The control of exercise intensity is an important factor to ensure the safety and efficacy of p hysical a ctivity i n a ny c ontext of application, both for athletic performance as for the recreational or therapeutic settings (Robertson, 2004). So, the individualized prescription of optimal and adequate exercise intensity is essential for improving health and reducing morbidity and mortality (Pedersen and Saltin, 2015). It has been demonstrated that monitoring the perception of the effort throughout scales to rate the perceived exertion (RPE) are effective methods to quantify and monitor the intensity of exercise (Day et al., 2004; Soriano-Maldonado et al., 2014). According to Pageaux (2016), perception of effort or exertion is a cognitive feeling of work associated with voluntary actions that can be assessed by the perception of the whole body (OB) or by the feeling experienced by the active muscle groups (AM). The use of the target number of repetitions and the RPE in chronic randomized clinical trials appears to be effective in determining the intensity of the elastic band training, once favorable outcomes (functional capacity, fat and fat-free mass, maximum strength) were obtained in short-term resistance training (Colado and Triplett, 2008; Colado et al., 2009; Colado et al., 2012a; Thiebaud et al., 2013).

Colado et al. (2012b) validated the OMNI-RES scale in young, healthy, physically active participants for monitoring the intensity during resistance exercises with elastic bands. However, as this scale has not been validated in the elderly (Colado et al., 2012b), its use in this population could be questioned. The perception of exertion can be considered a cognitive function that reflects the progressive a ging process (Guidetti et al., 2011), so the aging cognitive decline (Spirduso, 1995) could be a decreasing factor in the ability to consistently assign numbers to words or even pictures that describe exercise-related feelings (Dunbar and Kalinski, 2004; Groslambert and Mahon, 2006). As determined by Mays et al. (2010) few studies show evidence of cross-modal application of OMNI ratings of perceived exertion scales, hence justifying the necessity for the validation of OMNI scales that differ in the pictorial, numerical and/or verbal descriptors for specific exercise modes or type of population (Colado et al., 2014). In order to establish a concurrent validity of a new scale, one must correlate a criterion or stimulus variables (i.e., physiological and/or performance parameters as for example heart rate and total weight lifted) with a concurrent or response variable (i.e., RPE from a validity scale) (Lagally and Robertson, 2006). Also, any new scale's validation should provide information on its effectiveness for controlling the intensity between different training sessions (Colado et al., 2014). Accordingly, a validated scale for the elderly becomes necessary to have the assurance that its peculiarities are taken into account. Hence, the purposes of the present investigation were: (i) to examine the concurrent validity of the OMNI-RES Scale with elastic bands in elderly participants ( $>60$ years). (ii) To examine the effect of three different resistance exercise intensities with elastic bands on RPE, applied force, and heart rate responses; (iii) to determine the reliability of the session RPE method for quantifying intensity of the resistance training with elastic bands in the elderly using the elastic band resistance exercise scale. It was hypothesized that the RPE obtained from both AM and OB would show a positive link with applied force and heart rate during resistance exercises performed with elastic bands in elder population.

\section{Material and methods}

\subsection{Study design}

The investigation used a cross-sectional, perceptual estimation design consisting of one familiarization and two experimental trials. During the session of familiarization the participants were instructed on how to use the OMNI-Resistance Exercise Scale with elastic bands (Fig. 1) and also they were asked to establish the grip width on the elastic band with which they perform 15 maximum repetitions (RM) for the 4 prescribed exercises (i.e., shoulder abduction and elbow flexion, extension and abduction of hip). The next two assessment sessions were used to analyze the concurrent validity and reliability of the OMNI-RES scale for elastic bands. All dependent variables (RPE-AM and OB scores, applied force and heart rate) were measured in all the sets and exercise performed with the three analyzed intensities (low, medium and high).

\subsection{Participants}

Twenty-six participants ( 5 men and 21 women; $66.92 \pm 5.04$ years old; height $153.82 \pm 6.00 \mathrm{~cm}$; body mass $63.60 \pm 8.64 \mathrm{~kg}$; body mass index $26.87 \pm 3.37 \mathrm{~kg} / \mathrm{m}^{2}$ ) participated voluntarily. The inclusion cri-

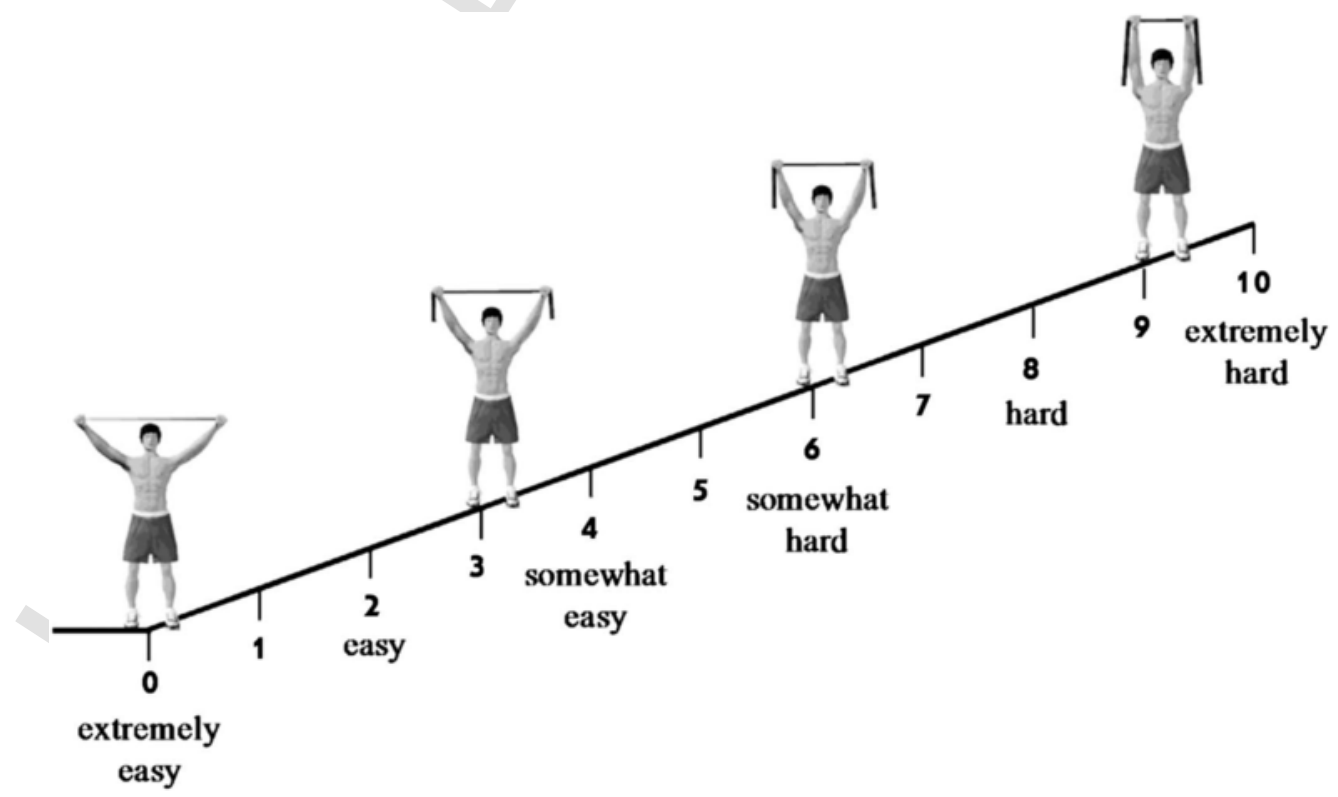

Fig. 1. OMNI-Resistance Exercise Scale of perceived exertion with TheraBand resistance bands. 
teria were (i) 6 months' minimum experience of physical activity and (ii) attendance at elastic band - training workout with a minimum frequency of twice per week during 3 weeks before the beginning of the study.

Participants taking performance-enhancing drugs at the time of the experiment; suffering musculoskeletal pain or any neuromuscular and cardiovascular disorder were excluded from the study. During the course of testing, participants were instructed to refrain from any non-experimental anaerobic or resistance exercise, maintain normal dietary habits, abstain from alcohol, caffeine, and nicotine for at least $24 \mathrm{~h}$ before the testing session. Before being included in the study, all participants were informed about the purpose, procedures, benefits, risks and discomfort that might result from participation in the present study. All participants were retirees and voluntarily agreed to participate; each of them provided informed consent and were free to withdraw from the study at any time. All experimental protocols were approved by the Ethics Committee of the University of Valencia (Spain) (H1464018006594). All applied procedures were in accordance with the requirements listed in the 1975 Declaration of Helsinki and its amendment in 2008.

\subsection{Familiarization session}

In this first session, the participants were familiarized with the exercises and the use of the scale for establishing the proper rating of perceived exertion. Proper instructions associated with low and high numerical categories as scale anchor points were provided. Participants carried out two different protocols, one of high and one of low intensity, to establish the range of values for perceived exertion and how they corresponded to the ratings on the OMNI-RES Thera-Band scale. The high-intensity protocol was carried out first, during which, the participants performed a set of 15RM and at the end, it was explained that the RPE-AM at that time corresponded to a rating of "10" on the OMNI-RES scale. During the low-intensity protocol, they performed a single repetition with a grip width that only allowed the elastic band to tighten very slightly at the end of the range of movement. At the end of this set, it was explained that RPE-AM at that time corresponded to a rating of " 0 " on the OMNI-RES scale. The $15 R M$ values were used to set the low and medium-intensities that were presented in the experimental session. Participants were not informed of the results of the 15RM assessment and were not aware of the intensities used during the experimental session until after they had completed the experiment. They were instructed to use the correct technique in the four exercises with the elastic band (TheraBand $($; Hygenic Corporation, Akron, OH, USA), avoiding any nonstandard movements. The exercises were performed using the dominant limbs (kick leg and throwing arm). Additionally, the grip width associated with the 15RM was also determined (Colado et al., 2012b; Newsam et al., 2005). The participants performed sets of each exercise, adjusting the grip width until they were able to perform 15RM. The recovery time between sets was 3 min.

\subsection{Experimental sessions}

Two identical measurement sessions, separated by $48 \mathrm{~h}$ were performed. After a standardized warm up participants performed 1 set of 15 low-intensity repetitions, 1 set of 15 medium-intensity repetitions and 1 set of high-intensity with 15RM. During the low-intensity set, the participants carried out the exercises with an elastic band grip width of $+50 \%$ over the width with which they achieved their $15 \mathrm{RM}$, during the medium-intensity set with an elastic band grip width of $+25 \%$ and with the grip identified for the 15RM during the high-intensity set. Each of the aforementioned intensities was used for each singular exercise: shoulder abduction, elbow flexion, e xtension a nd a bduction of hip. The order of the exercises and intensities was counterbalanced and randomized. The recovery time between sets was $2 \mathrm{~min}$. The sequence assigned to each participant was the same for the two experimental sessions. So, they were tested on 12 sets to obtain at the end of each one their applied force, heart rate, and RPE-AM and RPE-OB. The OMNI-RES scale was in clear view of the participants during the entire sessions. Participants were permitted to drink water ad libitum during the study sessions. The measurement protocols were always strictly controlled by the same researcher. Laboratory temperature was maintained in $20^{\circ} \mathrm{C}$ (Borreani et al., 2015).

\subsection{Exercises}

All participants were instructed to use the correct technique in the four exercises, avoiding any nonstandard movements. They were helped to maintain the correct position (and enhance the reproducibility of the experimental situation) through appropriate configuration of the measurement area (the subject's back or front, according with the exercise, was positioned as flat as possible against the wall). The range of movement for the two upper extremities exercises was set from a position at which the hand was touching the hip to $90^{\circ}$ for the shoulder abduction and to $135^{\circ}$ for the elbow flexion. For the two lower limb exercises the range of movement was from a standing position (aligned feet shoulder width apart) to $45^{\circ}$ for extension of the hip and to $30^{\circ}$ for the abduction of the hip. Range of colors used in the upper extremities exercises were from red to blue on the shoulder abduction and from blue to gold on the elbow flexion; range of colors used in both lower extremities exercises were from black to gold + black combined.

A digital metronome set at 70 beats.min during the experimental session paced repetition speed to ensure that the different exercises and sets were always performed at the same pace. Participants were asked to perform each repetition in a 2-count-up, 2- count-down pattern. Therefore, 1 repetition was performed for every 4 beats of the metronome. At this pace, each repetition lasted for approximately $3 \frac{1}{2} \mathrm{~s}$. This pace was selected because it was a reasonable pace at which to perform both very light (40\% 1RM) and very heavy (90\% 1RM) activity (Lagally and Robertson, 2006).

\subsection{Heart rate measurement}

Heart rate monitors (Polar FT1, Polar Electro, Tampere, Finland) were attached around the chests of the participants with an elastic band. The reading given by the pulsometer when the subject immediately performed the 15th repetition of each series was recorded and stored for later analysis.

\subsection{Applied force measurement}

A S-shaped load cell (Isocontrol; ATE micro, Madrid, Spain) was used to measure the applied force/weight (kg's). It is known that load cell is suitable instrument to quantify the variable resistive forces associated with elastic bands since there were no significant differences in force outputs between it and the force plate measurements (McMaster et al., 2010). The elastic band was engaged to one extremity of the cell, which converted force into a measurable electrical output sent to a computer through the other extremity. The reading given by the load cell during the 15 repetitions of each series was recorded and stored for later analysis.

\subsection{Statistical analyses}

Statistical analysis was performed using the Matlab (The MathWorks, Inc., Natick, MA, USA, version R2015a, licensed from the University of Valencia) software. All variables were initially checked for 
normality using Kolmogorov-Smirnov test. Data results are reported as mean and standard deviation (SD). A three-way (exercise [4] X intensity [3] X condition [2]) analysis of variance (ANOVA) was performed to determine the existence of differences between intensities in the applied force and in the OMNI-Resistance Exercise Scale scores for the different exercises. Also, a two-way ANOVA (Exercise [4] X intensity [3]) was performed to determine the intensity effect on the heart rate. Post hoc analysis with Bonferroni correction was used in the case of significant differences in the ANOVA models. Finally, the reliability of the applied force, OMNI-RES scores and heart rate measures was checked by means of intraclass correlation coefficient (ICC). The level of significance was set at $\mathrm{p} \leq 0.05$ before Bonferroni correction.

\section{Results}

\subsection{Applied force}

Table 1 shows the mean (SD) values of the applied force measured at the three assessed intensities. Significant differences between the high and low intensity for maximum force in the shoulder abduction exercise were found. Furthermore, in the elbow flexion, s ignificant differences were found both between the high and medium and the high and low intensities, as also between the medium and low intensity for the maximum force. In the lower extremities exercises (hip abduction and hip extension) significant differences were found between all the intensity levels for both maximum and medium force.

Table 1

Differences in applied force (kilograms) between intensities.

\begin{tabular}{|c|c|c|c|c|}
\hline & & $\begin{array}{l}\text { High } \\
\text { intensity }\end{array}$ & $\begin{array}{l}\text { Medium } \\
\text { intensity }\end{array}$ & $\begin{array}{l}\text { Low } \\
\text { intensity }\end{array}$ \\
\hline \multirow[t]{2}{*}{$\begin{array}{l}\text { Shoulder } \\
\text { abduction }\end{array}$} & Mean & $\begin{array}{l}1.22 \\
(0.55)\end{array}$ & $0.80(0.36)$ & $\begin{array}{l}0.54 \\
(0.26)\end{array}$ \\
\hline & Max. & $\begin{array}{l}4.53 \\
(1.28)^{*}\end{array}$ & $3.75(0.96)$ & $\begin{array}{l}3.27 \\
(0.96)\end{array}$ \\
\hline \multirow[t]{2}{*}{ Elbow flexion } & Mean & $\begin{array}{l}3.72 \\
(1.48)\end{array}$ & $2.62(1.01)$ & $\begin{array}{l}1.71 \\
(0.73)\end{array}$ \\
\hline & Max. & $\begin{array}{l}9.82 \\
(2.33)^{\dagger, *}\end{array}$ & $7.82(2.14)^{\S}$ & $\begin{array}{l}6.56 \\
(1.93)\end{array}$ \\
\hline \multirow[t]{2}{*}{ Hip abduction } & Mean & $\begin{array}{l}2.79 \\
(1.53)^{\dagger, *}\end{array}$ & $1.19(0.74)^{8}$ & $\begin{array}{l}0.32 \\
(0.27)\end{array}$ \\
\hline & Max. & $\begin{array}{l}11.18 \\
(3.48)^{\dagger, *}\end{array}$ & $7.01(2.28)^{\S}$ & $\begin{array}{l}3.20 \\
(1.97)\end{array}$ \\
\hline \multirow[t]{2}{*}{ Hip extension } & Mean & $\begin{array}{l}5.32 \\
(2.34)^{\dagger, *}\end{array}$ & $2.76(1.27)^{\S}$ & $\begin{array}{l}1.15 \\
(0.69)\end{array}$ \\
\hline & Max. & $\begin{array}{l}17.48 \\
(4.97)^{\dagger, *}\end{array}$ & $\begin{array}{l}12.33 \\
(2.74)^{\S}\end{array}$ & $\begin{array}{l}7.93 \\
(2.46)\end{array}$ \\
\hline
\end{tabular}

Data are expressed as mean (Standard Deviation) of the applied force (force/weight) for the maximum and mean values obtained during the 15 repetitions at the different intensities (i.e. different grip widths).

$\star$ Significant differences $(\mathrm{p}<0.001)$ between high and medium intensities.

* Significant differences $(\mathrm{p}<0.001)$ between high and low intensities.

$\S$ Significant differences $(\mathrm{p}<0.001)$ between medium and low intensities.

Table 3

Differences in OMNI-Resistance Exercise Scale scores.

\begin{tabular}{|c|c|c|c|c|c|c|}
\hline & Active muscles & & & Overall & & \\
\hline & High & Medium & Low & High & Medium & Low \\
\hline Shoulder abduction & $9.35(0.80)^{\dagger, *}$ & $7.27(1.31)^{\S}$ & $5.27(1.80)$ & $6.04(1.64)^{*}$ & $4.92(2.15)$ & $4.04(1.89)$ \\
\hline Elbow flexion & $9.50(1.03)^{\dagger, *}$ & $7.04(1.40)^{\S}$ & $5.00(1.50)$ & $6.50(1.66)^{\dagger, *}$ & $5.04(1.87)$ & $3.73(1.37)$ \\
\hline Hip abduction & $9.04(1.31)^{\dagger, *}$ & $5.96(1.87)^{\S}$ & $2.50(1.42)$ & $5.92(1.85)^{\dagger, *}$ & $4.35(1.92)^{\S}$ & $2.46(1.36)$ \\
\hline Hip extension & $8.88(1.07)^{\dagger, *}$ & $6.15(1.89)^{\S}$ & $3.81(1.90)$ & $6.50(1.94)^{\dagger, *}$ & $4.50(2.12)$ & $3.35(1.90)$ \\
\hline
\end{tabular}

Data are expressed as mean (Standard Deviation)

+ Significant differences $(\mathrm{p}<0.001)$ between high and medium intensities.

* Significant differences $(\mathrm{p}<0.001)$ between high and low intensities.

$\S$ Significant differences $(\mathrm{p}<0.001)$ between medium and low intensities.

Table 2

Differences in heart rate (bpm) between intensities.

\begin{tabular}{llll}
\hline & High intensity & $\begin{array}{l}\text { Medium } \\
\text { intensity }\end{array}$ & $\begin{array}{l}\text { Low } \\
\text { intensity }\end{array}$ \\
\hline $\begin{array}{l}\text { Shoulder } \\
\text { abduction }\end{array}$ & $\begin{array}{l}104.58 \\
(15.49)^{*}\end{array}$ & $99.50(14.69)$ & $\begin{array}{l}97.31 \\
(13.82)\end{array}$ \\
Elbow flexion & $\begin{array}{l}104.96 \\
(14.79)^{*}\end{array}$ & $100.19(14.86)$ & $\begin{array}{l}95.62 \\
(13.66)\end{array}$ \\
Hip abduction & 106.50 & $99.92(13.61)$ & 96.96 \\
Hip extension & $(14.74)^{*}$ & $100.46(14.50)$ & $\begin{array}{l}(13.28) \\
96.42\end{array}$ \\
& 107.38 & & $(13.88)$
\end{tabular}

Data are expressed as mean (Standard Deviation). Bpm = beats per minute.

* Significant differences $(\mathrm{p}<0.001)$ between high and low intensities.

\subsection{Heart rate}

Significant higher heart rate was observed in the high intensity than in the low intensity for all the exercises. However, no significant differences were found among the other intensities (Table 2).

\subsection{Rating of perceived exertion}

Regarding the values obtained of the OMNI-Resistance scale, the scores for the AM were significantly higher in the high-intensity set than in the medium-intensity and low-intensity sets for all the exercises. Also, the scores of the medium-intensity set are higher than in the low-intensity set. In the $\mathrm{OB}$, scores in the high-intensity set were higher than in the low-intensity set. These OMNI-Resistance scores are shown in Table 3 .

\subsection{Inter-session reliability}

The inter-session reliability analysis shows an excellent ICC for AM and good for OB in OMNI-RES Scale scores. Regarding the applied force results shown an excellent ICC for the mean force and maximum force, while in reference to heart rate was obtained also an excellent reliability. The results of ICC analysis are shown in Table 4.

\section{Discussion}

The present study demonstrates the suitability of the OMNI-RES scale for elastic bands to monitor the exercise intensity in elder participants. The findings of this study supported that both the RPE-AM and RPE-OB would represent a positive linkage with the applied force and the heart rate response in elderly people when training with elastic bands. Additionally, the RPE-AM values seem to be higher than RPE-OB during each set of upper- and lower-body resistance exercise. Additionally, a reduction in the elastic band grip width resulted in an increase in the applied force, heart rate response and the corresponding 
Intersessions reliability of OMNI-Resistance Exercise Scale, applied force and heart rate scores.

\begin{tabular}{ll}
\hline & OMNI-Resistance \\
\hline Active muscles & $0.80(0.04)$ \\
Overall body & $0.69(0.07)$ \\
\hline & Applied force \\
\hline Average force & $0.86(0.03)$ \\
Max force & $0.76(0.13)$ \\
\hline Heart rate & \\
\hline $0.79(0.02)$ & \\
\hline
\end{tabular}

Data are expressed as ICC (Standard Deviation).

ICC $=$ intraclass correlation coefficient. Reliability interpretation values: $<0.40$ is poor; 0.40 to 0.59 is fair; 0.60 to 0.74 is good; and $>0.74$ to 1.00 is excellent.

RPE-AM and OB. A concurrent paradigm has been used to corroborate the application of the OMNI-RES scale of perceived exertion with elastic bands for resistance exercises to different populations to those used in the original study by Colado et al. (2012b). Consequently the OMNI-RES scale of perceived exertion with elastic bands for resistance exercises has been validated in this study for the elderly population.

Regarding the level of applied force, the present results are in the lines of others studies using Borg scales that have demonstrated a positive association between the RPE score and the total weight lifted (Gearhart et al., 2002; Pierce et al., 1993; Lagally and Robertson, 2006). Our study used elastic bands in which the level of applied resistance is controlled by altering the grip width. This fact is endorsed by the differences in the applied force observed between the high and low intensity.

In addition to other factors, the adjustments of the cardiovascular system during the exercise are also dependent on the increase of the recruitment of muscular fibers, so that autonomic nervous system and its afferents sympathetic and parasympathetic modulates the heart rate in accordance with demand imposed, increasing the number of heart beats according at the magnitude of the intensity of the strength exercise (Quitério et al., 2011). In this investigation, the heart rate was considered a physiologic analog of the applied force for each set of the different exercises (Miller et al., 2009; Quitério et al., 2011; Rozenek et al., 1993). Therefore, heart rate served as a co-criterion variable with the applied force in assessing concurrent RPE responsiveness during the different intensities (Miller et al., 2009). Considering the high intensity, the average heart rate ranged from low intensity a $7.47 \%$ in the shoulder abduction exercise, a $9.77 \%$ in the elbow flexion exercise, a $9.84 \%$ in the hip abduction exercise and a $11.37 \%$ in the hip extension exercise, providing sufficient response differences for correlational analysis. The observed differences in the physiological (heart rate) and perceptual variables in response to changes in resistance exercise intensity through elastic band grip width are in the line with previous studies (Colado et al., 2014). With an applied perspective, the present findings confirmed that a reduction in elastic band grip width is related to an increase in heart rate and $\mathrm{AM}$ and $\mathrm{OB}$ perception of the exertion associated with the exercise being performed; which might indicate that this is an appropriate, safe and useful tool for monitoring heart rate in older populations during elastic band resistance exercises. The excellent reliability of the heart rate was also observed across sessions.

It is known that a positive responsiveness of RPE has been admitted as a way of concurrent validation of perceived exertion category scales for both female and male adult (Mays et al., 2010). The present investigation is the first to examine the concurrent validity of a pictorial-verbal category scale of perceived exertion for use with elastic bands by female and male older adults during upper- and lower-body resistance exercise. Using the OMNI RES, both RPE-AM and RPE-OB were measured during the last repetition for each of the three-resistance exercise sets intensities. The RPE-AM was higher than the RPE-OB in all exercise and for the three analyzed intensities. One of the utility of a category RPE scale is its precision when differentiating an anatomically regionalized perceptual signal and a total body signal when both assessments are made within a comparatively narrow time frame (Robertson et al., 2001), therefore we can warrant that the OMNI-RES scale is accurate and valid in monitoring the responsiveness of active-muscle RPE with older adults performing resistance exercise at different intensities with bands. Our result proved that older adults can use the OMNI-RES scale to transform into numbers their perceptions of physical exertion during both upper- and lower-body exercises. Taking into account the strong positive and linear relationship observed between RPE and both heart rate and applied force, we can assume that it provides concurrent validity evidence for the use of the OMNI-RES scale by older adults during resistance exercise. This investigation followed the same methodological guidelines regarding the characteristics of previous studies (Colado et al., 2012b; Lagally et al., 2002; Robertson et al., 2003) but with the advantage that the concurrent validation has been performed with the evaluation of four exercises (two for upper body and two for lower body) versus only two exercises (one of each) used in the previous investigations. Additionally, the present study used three different intensities for each of the performed exercises. Indeed, using the TheraBand scale to quantifying resistance training intensity demonstrated to a reliable method to measure RPE and force production across the two training sessions. The observed reliability could explain the effectiveness obtained in previous studies with similar population in which the targeted number of repetitions was maintained while applying the OMNI-RES $\mathrm{AM}$ in medium-term elastic band resistance programs (Chupel et al., 2017; Muntaner-Mas et al., 2017).

The obtained results may have important implications for exercise prescription and might bring some valuable information to researchers and trainers by assisting in the development and management of resistance-training programs in the elderly population. Coaches and clinician will be able to accurately distinguish between different levels of intensity using the same material (i.e. elastic bands), and consequently select vary the proper training load for individuals with different levels of physical activity based on the previously defined goals (Day et al., 2004; Robertson et al., 2005).

\section{Conclusions}

The present study showed that the OMNI-RES with elastic bands scale is a suitable tool for controlling resistance training intensity with older adults. The validated scale can be used during different resistance exercises allowing the stimulus regime to be applied more effectively when performing strength training. Thus, the OMNI-RES scale with elastic bands can be considered an appropriate, valid and useful tool for assessing perceived exertion of OA, contributing an important added value at this cheap and accessible device. However, future studies should confirm these findings with other elder populations and with even more technically complex exercises (i.e. multi-joint exercises).

\section{Acknowledgments}

The authors thanks to the participants for their excellent cooperation, to Víctor Cutillas and Pablo García for assisting during measurements, and to the Physiotherapy Department of University of Valencia (Spain) for facilitating the space for developing the study.

This research did not receive any specific grant from funding agencies in the public, commercial, or not-for-profit sectors. 


\section{References}

Borreani, S., Calatayud, J., Colado, J.C., Tella, V., Moya-Nájera, D., Martin, F., Rogers, M.E., 2015. Shoulder muscle activation during stable and suspended push-ups at different heights in healthy subjects. Phys. Ther. Sport 16, 248-254. https://doi.org/10. 1016/j.ptsp.2014.12.004, (Epub 2014 Dec 18).

Chodzko-Zajko, W.J., Proctor, D.N., Fiatarone Singh, M.A., Minson, C.T., Nigg, C.R., Salem, G.J., Skinner, J.S., American College of Sports Medicine, 2009. American College of Sports Medicine position stand. Exercise and physical activity for older adults. Med. Sci. Sports Exerc. 41, 1510-1530. https://doi.org/10.1249/MSS. 0b013e3181a0c95c.

Chupel, M.U., Direito, F., Furtado, G.E., Minuzzi, L.G., Pedrosa, F.M., Colado, J.C., Ferreira, J.P., Filaire, E., Teixeira, A.M., 2017. Strength training decreases inflammation and increases cognition and physical fitness in older women with cognitive impairment. Front. Physiol. 8 (377)https://doi.org/10.3389/fphys.2017.00377.

Colado, J.C., Triplett, N.T., 2008. Effects of a short-term resistance program using elastic bands versus weight machines for sedentary middle-aged women. J. Strength Cond. Res. 22, 1441-1448. https://doi.org/10.1519/JSC.0b013e31817ae67a.

Colado, J.C., Triplett, N.T., Tella, V., Saucedo, P., Abellán, J., 2009. Effects of aquatic resistance training on health and fitness in postmenopausal women. Eur. J. Appl. Physiol. 106, 113-122. https://doi.org/10.1007/s00421-009-0996-7.

Colado, J.C., Garcia-Masso, X., Rogers, M.E., Tella, V., Benavent, J., Dantas, E.H., 2012. a. Effects of aquatic and dry land resistance training devices on body composition and physical capacity in postmenopausal women. J. Hum. Kinet. 32, 185-195. https://doi. org/10.2478/v10078-012-0035-3

Colado, J.C., Garcia-Masso, X., Triplett, N.T., Flandez, J., Borreani, S., Tella, V., 2012. Concurrent validation of the OMNI-Resistance Exercise Scale of perceived exertion with Thera-band resistance bands. J. Strength Cond. Res. 26, 3018-3024. https://doi.org/ 10.1519/JSC.0b013e318245c0c9.

Colado, J.C., Garcia-Masso, X., Triplett, N.T., Calatayud, J., Flandez, J., Behm, D., Rogers, M.E., 2014. Construct and concurrent validation of a new resistance intensity scale for exercise with thera-band $®$ elastic bands. J. Sports Sci. Med. 13, 758-766.

Day, M.L., McGuigan, M.R., Brice, G., Foster, C., 2004. Monitoring exercise intensity during resistance training using the session RPE scale. J. Strength Cond. Res. 18, 353-358. https://doi.org/10.1519/R-13113.1.

Delmonico, M.J., Harris, T.B., Lee, J.S., Visser, M., Nevitt, M., Kritchevsky, S.B., Tylavsky, F.A., Newman, A.B., Aging and Body Composition Study, 2007. Alternative definitions of sarcopenia, lower extremity performance, and functional impairment with aging in older men and women. J. Am. Geriatr. Soc. 55, 769-774. https://doi.org/10.1111/j. 1532-5415.2007.01140.x.

Dunbar, C.C., Kalinski, M.I., 2004. Using RPE to regulate exercise intensity during a 20-week training program for postmenopausal women: a pilot study. Percept. Mot. Skills 99, 688-690. https://doi.org/10.2466/pms.99.2.688-690.

Gearhart, R.F., Goss, F.L., Lagally, K.M., Jakicic, J.M., Gallagher, J., Gallagher, K.I., Robertson, R.J., 2002. Ratings of perceived exertion in active muscle during high-intensity and low-intensity resistance exercise. J. Strength Cond. Res. 16, 87-91. https: //doi.org/10.1519/00124278-200202000-00013.

Groslambert, A., Mahon, A.D., 2006. Perceived exertion: influence of age and cognitive development. Sports Med. 36, 911-928. https://doi.org/10.2165/ 00007256-200636110-00001.

Guidetti, A., Sgadari, A., Buzzachera, F.C., Broccatelli, M., Utter, A.C., Goss, F.L., Baldari, C., 2011. Validation of the OMNI-cycle scale of perceived exertion in the elderly. J. Aging Phys. Act. 19, 214-224. https://doi.org/10.1123/japa.19.3.214.

José, A., Dal Corso, S., 2016. Inpatient rehabilitation improves functional capacity, peripheral muscle strength and quality of life in patients with community-acquired pneumonia: a randomized trial. J Physiother. 62, 96-102. https://doi.org/10.1016/j.jphys. 2016.02.014.

Lagally, K.M., Robertson, R.J., 2006. Construct validity of the OMNI resistance exercise scale. J Strength Cond. Res. 20, 252-256. https://doi.org/10.1519/R-17224.1.

Lagally, K.M., Robertson, R.J., Gallagher, K.I., Goss, F.L., Jakicic, J.M., Lephart, S., Goodpaster, B., 2002. Perceived exertion, electromyography, and blood lactate during acute bouts of resistance exercise. Med. Sci. Sports Exerc. 34, 552-559. https://doi. org/10.1097/00005768-200203000-00025.

Mally, K., Trentmann, J., Heller, M., Dittmar, M., 2011. Reliability and accuracy of segmental bioelectrical impedance analysis for assessing muscle and fat mass in older Europeans: a comparison with dual-energy X-ray absorptiometry. Eur. J. Appl. Physiol. 111, 1879-1887. https://doi.org/10.1007/s00421-010-1795-x.
Martins, W., de Oliveira, R., Carvalho, R., de Oliveira, V., da Silva, V., Silva, M., 2013. Elastic resistance training to increase muscle strength in elderly: a systematic review with meta-analysis. Arch. Gerontol. Geriatr. 57, 8-15. https://doi.org/10.1016/ j.archger.2013.03.002.

Mays, R.J., Goss, F.L., Schafer, M., Kim, K.H., Nagle-Stilley, E.F., Robertson, R.J., 2010 Validation of adult OMNI perceived exertion scales for elliptical ergometry. Percept. Mot. Skills 111, 848-862. https://doi.org/10.2466/05.06.PMS.111.6.848-862.

McMaster, D.T., Cronin, J., McGuigan, M.R., 2010. Quantification of rubber and chain-based resistance modes. J Strength Cond. Res. 24, 2056-2064. https://doi.org/ 10.1519/JSC.0b013e3181dc4200.

Miller, P.C., Hall, E.E., Chmelo, E.A., Morrison, J.M., DeWitt, R.E., Kostura, C.M., 2009 The influence of muscle action on heart rate, RPE, and affective responses after upper-body resistance exercise. J. Strength Cond. Res. 23, 366-372. https://doi.org/10. 1519/JSC.0b013e31818548f6.

Muntaner-Mas, A., Vidal-Conti, J., Borràs, P.A., Ortega, F.B., Palou, P., 2017. Effects of a Whatsapp-delivered physical activity intervention to enhance health-related physical fitness components and cardiovascular disease risk factors in older adults. J. Sports Med. Phys. Fitness 57, 90-102. https://doi.org/10.23736/S0022-4707.16.05918-1.

Newsam, C.J., Leese, C., Fernandez-Silva, J., 2005. Intratester reliability for determining an eight-repetition maximum for three shoulder exercises using elastic bands. J. Sport Rehabil. 14, 35-47. https://doi.org/10.1123/jsr.14.1.35.

Pageaux, B., 2016. Perception of effort in exercise science: definition, measurement and perspectives. Eur. J. Sport Sci. 16, 885-894. https://doi.org/10.1080/17461391. 2016.1188992.

Pedersen, B.K., Saltin, B., 2015. Exercise as medicine - evidence for prescribing exercise as therapy in 26 different chronic diseases. Scand. J. Med. Sci. Sports 25 (Suppl. 3), 1-72. https://doi.org/10.1111/sms.12581.

Pierce, K., Rozenek, R., Stone, M.H., 1993. Effects of high volume weight training on lactate, heart rate and perceived exertion. J Strength Cond. Res. 7, 211-215. https://doi. org/10.1519/00124278-199311000-00004.

Polyte, P.J.J., Belando, N., Huéscar, E., Moreno-Murcia, J.A., 2015. Effect of style teaching in the motivation of women practitioners of physical exercise. Acción Psicol. 12, 57-64. https://doi.org/10.5944/ap.12.1.13977.

Quitério, R.J., Melo, R.C., Takahashi, A.C.M., Aniceto, I.A.V., Silva, E., Catai, A.M., 2011. Torque, myoelectric signal and heart rate responses during concentric and eccentric exercises in older men. Rev. Bras. Fisioter. 15, 8-14. https://doi.org/10.1590/ S1413-35552011005000004.

Robertson, R.J., 2004. Perceived Exertion for Practitioners. Human Kinetics, Champaign, IL.

Robertson, R.J., Goss, F.L., Boer, N.F., Gallagher, J.D., Thompkins, T., Bufalino, K., Balasekaran, G., Meckes, C., Pintar, J., Williams, A., 2001. OMNI scale of perceived exertion at ventilatory breakpoint in children: response normalized. Med. Sci. Sports Exerc. 33, 1946-1952. https://doi.org/10.1097/00005768-200111000-00022.

Robertson, R.J., Goss, F.L., Rutkowski, J., Lenz, B., Dixon, C., Timmer, J., Andreacci, J., 2003. Concurrent validation of the OMNI perceived exertion scale for resistance exercise. Med. Sci. Sports Exerc. 35, 333-341. https://doi.org/10.1249/01.MSS. $0000048831.15016 .2 \mathrm{~A}$.

Robertson, R.J., Goss, F.L., Andreacci, J., Dubé, J., Rutkowski, J., Frazee, K.M., Aaron, D.J., Metz, K.F., Kowallis, R.A., Snees, B.M., 2005. Validation of the children's OMNI-Resistance Exercise Scale of perceived exertion. Med. Sci. Sports Exerc. 37, 819-826. https://doi.org/10.1249/01.MSS.0000162619.33236.

Rossi, A.P., Bianchi, L., Volpato, S., Bandinelli, S., Guralnik, J., Zamboni, M., Ferrucci, L., 2017. Dynapenic abdominal obesity as a predictor of worsening disability, hospitalization, and mortality in older adults: results from the InCHIANTI study. J. Gerontol. A Biol. Sci. Med. Sci. 1, 1098-1104. https://doi.org/10.1093/gerona/glw203.

Rozenek, R.L., Rosenau, L., Rosenau, P., Stone, M.H., 1993. The effect of intensity on heart rate and blood lactate response to resistance exercise. J. Strength Cond. Res. 7, 51-54. https://doi.org/10.1519/00124278-199302000-00010.

Soriano-Maldonado, A., Romero, L., Femia, P., Roero, C., Ruiz, J.R., Gutiérrez, A., 2014. A learning protocol improves the validity of the Borg 6-20 RPE scale during indoor cycling. Int. J. Sports Med. 35, 379-384. https://doi.org/10.1055/s-0033-1353166.

Spirduso, W.W., 1995. Physical Dimensions of Aging. Human Kinetics, Champaign, IL.

Thiebaud, R.S., Loenneke, J.P., Fahs, C.A., Rossow, L.M., Kim, D., Abe, T., Anderson, M.A., Young, K.C., Bemben, D.A., Bemben, M.G., 2013. The effects of elastic band resistance training combined with blood flow restriction on strength, total bone-free lean body mass and muscle thickness in postmenopausal women. Clin. Physiol. Funct. Imaging 33, 344-352. https://doi.org/10.1111/cpf.12033. 